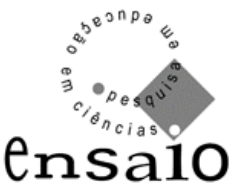

\title{
A CONFIABILIDADE E A VALIDAÇÃO NA INVESTIGAÇÃO EPISTEMOLÓGICA DO LIVRO DIDÁTICO DE QUÍMICA: UM DESENHO METODOLÓGICO.
}

\section{THE RELIABILITY AND VALIDATION ON THE TEXTBOOK CHEMISTRY EPISTEMOLOGICAL RESEARCH: A METHODOLOGICAL DESIGN.}

\author{
Geraldo José da Silva* \\ Carmen Maria De Caro Martins ${ }^{* *}$
}

\begin{abstract}
Resumo
Neste trabalho, apresentamos um estudo sobre a natureza epistemológica da visão da ciência presente em livros didáticos de Química. Realizamos um estudo que tinha como objetivo investigar a visão de ciência explícita e implícita presente em livros didáticos de química e o tratamento dado à história da ciência e à relação entre ciência, tecnologia e sociedade. Apresentamos um desenho metodológico construído para identificar marcas textuais em fragmentos semânticos selecionados no livro didático analisado. A metodologia desenvolvida baseia-se na confiabilidade e validação das categorias desenvolvidas por meio da concordância intercodificadores. Apresentamos também a análise do perfil epistemológico de um livro didático discutindo as possíveis decorrências pedagógicas.
\end{abstract}

Palavras-chave: Currículo. Epistemologia-em-uso. Livro Didático. Confiabilidade. Ensino de Química.

\begin{abstract}
In this work we present a study on the epistemological nature of this vision of science in textbooks for chemistry. We performed a study which was designed to investigate the vision of science explicitly and implicitly present in textbooks for chemistry and the treatment given to the history of science and the relationship between science, technology and society. We present a methodological design built to identify textual evidence (textual marks) in chapter's semantic fragments of textbook analysis, based on the search for categories reliability and validity developed by the intercoders agreement. We also present the epistemological profile analysis of a textbook discussing their educational consequences.
\end{abstract}

Keywords: Curriculum. Epistemology. Textbooks. Reliability. Chemistry Teaching.

\footnotetext{
* Faculdade Pitágoras/Programa de Pós-graduação FAE/UFMG, geraldo jsilva@yahoo.com.br

${ }^{* *}$ Universidade Federal de Minas Gerais/Colégio Técnico e Programa de Pós-graduação em Educação.
} 


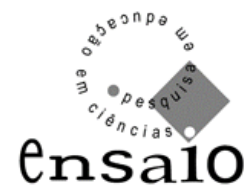

\section{INTRODUÇÃO}

\subsection{Como investigar a natureza epistemológica da visão da ciência presente nos livros didáticos?}

Os referenciais teóricos para a elaboração das categorias utilizadas na análise da imagem da ciência nos livros didáticos de Química tiveram origem nos trabalhos de Campos e Cachapuz (1997). A partir das categorias desenvolvidas por Campos e Cachapuz, desenvolvemos duas categorias qualitativas para dimensões epistemológicas que se contrapõem: 1. Empirista/indutivista e 2. Racionalista/dedutivista.

Nosso desafio é como identificar, em um livro didático, o posicionamento epistemológico apresentado. Campos e Cachapuz (1997) analisam o livro didático a partir de duas categorias que construíram. Nessa abordagem, o livro didático é tratado como um todo e é enquadrado, pela percepção do pesquisador, nas categorias de análise.

Se, de um lado, nesse desenho existe o mérito do tratamento holístico, por outro, debilita-se a compreensão das razões que levaram o pesquisador a enquadrar o livro em uma dada categoria. Podemos argumentar que essa metodologia é muito subjetiva por não explicitar as marcas ou indícios que levam a tal categorização. Esse esquema de categorização holística seria problemático se aplicado ao julgamento de questões abertas em uma prova ou de um portifólio escolar. Há duas ordens de problemas, uma diz respeito à baixa confiabilidade desse procedimento metodológico, a outra diz respeito à própria natureza da relação entre dados, evidência e conclusão.

A noção clássica de confiabilidade, nascida no contexto das pesquisas quantitativas na tradição psicométrica, advém de se considerar a seguinte questão: "se os sujeitos são testados duas vezes, os dois escores irão concordar entre si?" (CRONBACH, 1990, p.191). Transladada para o contexto da categorização de textos, a pergunta poderia ser traduzida em: se um texto for codificado em dois momentos distintos, irão os códigos coincidir? Ou ainda, se dois codificadores distintos codificam o mesmo texto, irão os códigos coincidir? A primeira questão parece uma 


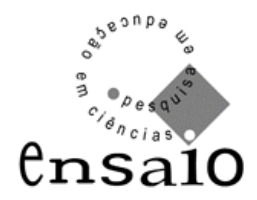

obviedade, mas não é. Não se trata apenas da estabilidade do esquema de codificação, mas da possibilidade de leituras distintas de um mesmo texto em virtude do conhecimento do codificador ter se alterado. É sabido que a leitura depende do conhecimento do mundo do leitor (SMITH, 1989). E o conhecimento do mundo muda se o codificador já fez muitas codificações. Como nos alertam Miles e Huberman (1987), "não são as palavras em si, mas seus significados que importam" (p.56). Eles também nos alertam que categorizar ou "codificar é fazer análise” (p.56), isto é, exige fazer escolhas, tomar posições, interpretar, o que exclui outras escolhas e posições, outras categorizações. Se categorizar é analisar e se "uma frase não contém um significado como um frasco contém a água”, mas seu significado é atribuído pelo leitor em um dado contexto e momento da leitura, um mesmo codificador pode não manter estabilidade na codificação e interpretação ao longo do tempo. Todos aqueles que têm experiência em corrigir provas de alunos sabem disso e dessa dificuldade.

O problema relativo à natureza da relação entre dados, evidência e conclusão está relacionado a uma visão simplista de que (i) dados são evidências e (ii) aceita a existência de evidências, a conclusão está implicada nelas. A primeira visão é mais simples de discutir e esclarecer. Dados não são fatos brutos, informações do mundo "tal como ele é". Dados são construções do pesquisador e refletem sua perspectiva de pesquisa: "a coleta de dados é inescapavelmente um processo seletivo" (MILES \& HUBERMAN, 1994, p.55). Por outro lado, evidências são também construções do pesquisador, mas construções de uma natureza diferente dos dados. De fato, se dados são construídos pelo pesquisador, eles em si não são evidências:

Um conjunto de dados torna-se uma evidência em algum problema analítico quando é estabelecida a sua relevância para uma ou mais hipóteses sob consideração... Evidência é relevante em alguma hipótese se ela ou aumenta ou diminui a probabilidade da hipótese. Sem hipóteses não se pode estabelecer a relevância de nenhum conjunto de dados. (SCHUM, 1987, p.16).

Isso significa que se dados são construídos pelos filtros da perspectiva do pesquisador, as evidências dependem da teoria e da formulação do problema pelo pesquisador. Vê-se, pelo argumento de Schum que as evidências não decorrem dos dados, elas se baseiam nas hipóteses criadas pelo pesquisador para ligar dados e teoria. E, finalmente, dado que uma evidência foi construída, ela pode fortalecer ou 


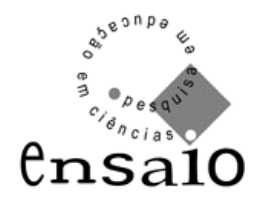

enfraquecer nossa crença na veracidade da hipótese. E as evidências não têm todas a mesma força ou o mesmo poder de convicção. Myslevy (1994) dá um exemplo de como as evidências se encadeiam em um raciocínio para sustentar uma conclusão: ele descreve como um grupo de juízes analisa um portifólio específico e lhe atribui uma nota. O exemplo de Mislevy ilustra a idéia expressa por Twining (1986) sobre a ligação entre evidência e inferência:

Os conceitos básicos incluem conjunção, proposições compostas, corroboração, convergência e inferências concatenadas (inferências sobre inferências)... Cada uma dessas noções levanta questões difíceis sobre o que está envolvido em se determinar a força probativa geral ou o peso da evidência. (Twining, 1986)

Ao fazerem a categorização sem tornar explícitas suas razões, Campos e Cachapuz não nos oferecem a chance de avaliar a força de cada evidência, e, ao final, a adequação de sua categorização.

Mas nem todos os pesquisadores acham tais noções adequadas para a pesquisa qualitativa. Segundo Hruschka et al. (2004), há três atitudes entre os pesquisadores em relação ao uso da noção de confiabilidade das codificações nas pesquisas qualitativas: (i) a primeira sustenta que a pesquisa qualitativa constitui-se em um paradigma distinto e que a noção de confiabilidade originada nas tradições de pesquisa "positivista" e quantitativa não deve ser usada neste tipo de pesquisa; (ii) a segunda é a que demonstra um ceticismo sobre a possibilidade de se gerar codificações confiáveis, dada a natureza subjetiva da análise qualitativa. Nesta perspectiva, entende-se que gerar codificações confiáveis de texto é impossível ou, no máximo, de importância menor; e (iii) a terceira reconhece que a noção de confiabilidade das codificações é uma noção muito útil nos cenários caracterizados pelo trabalho aplicado, multidisciplinar ou, ainda, baseado em equipes de trabalho. Miles e Huberman (1994, p.277) relatam em seu livro que fizeram uma sondagem entre pesquisadores qualitativos sobre a questão da qualidade dos resultados da pesquisa e identificaram duas posições: uma que achava a noção útil no contexto da justificação, como para convencer os pesquisadores do paradigma quantitativo ou "positivista" que a pesquisa qualitativa naturalística não usa métodos mais imprecisos ou enviesados do que a deles. A segunda posição considera a noção útil no próprio contexto da pesquisa qualitativa e não apenas como um dispositivo justificatório. No entanto, Miles e 


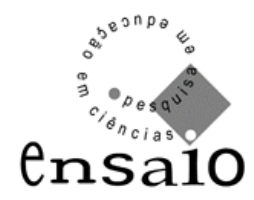

Huberman reconhecem ser esse um tema controverso e, apesar disso, acham que a noção de validação da pesquisa precisa ser discutida e considerada. Dentre os diversos tipos de validação que discutem, está a da objetividade e confirmabilidade dos resultados. Essa noção está ligada a quanto as conclusões dependem dos sujeitos ou das condições da pesquisa, e é também chamada de confiabilidade externa. Um segundo tipo de validação lida com a confiabilidade, a dependabilidade, a auditabilidade da pesquisa. Aqui a questão básica é se os processos da investigação são consistentes e têm uma razoável estabilidade no tempo e entre pesquisadores e métodos. Aqui se encaixa a noção de que um bom sistema de categorização precisa ser razoavelmente independente do pesquisador, claramente enunciar os critérios e princípios de codificação. A confiabilidade intercodificadores é o processo para assegurar essas qualidades. É ela que geralmente faz falta na metodologia utilizada para a análise epistemológica do livro didático. É exatamente o ingrediente fundamental do desenho metodológico que escolhemos utilizar.

Neste trabalho, agregamos a necessidade de a pesquisa epistemológica do livro didático possibilitar a investigação da dimensão tácita do conhecimento (POLANYI, 1983). Argyris e Schön (1974) demonstraram em seus trabalhos que as teorias que utilizamos, por um lado, são teorias expostas, verbalizadas (exposed) que, geralmente, apresentam caráter justificatório de nossa ação e, por outro, são teorias-de-uso, que não sabemos expor, mas constituem elementos efetivos na nossa maneira de agir.

A dimensão tácita também aparece nos trabalhos de Gerard Vergnaud (CAMPOS CONCEITUAIS, 1988) sobre a cognição. Essa teoria ressalta que a conceitualização é o eixo central da cognição e que se expressa em três conjuntos interligados: 1) conjunto de atividades propostas (que dão sentido ao conceito), 2) conjunto da representação simbólica utilizada (os significantes desse conceito) e 3) conjunto dos invariantes operatórios que permite o sujeito dominar e atuar em uma determinada situação. Os invariantes operatórios são conceitos-em-ação ou teoriasem-ação (o significado de um conceito), que muitas vezes está situado na dimensão tácita do conhecimento.

A "epistemologia exposta", isto é, a natureza da ciência explicitamente defendida (verbalizada), geralmente na introdução de um livro didático corresponde à "epistemologia-em-uso", isto é, a natureza da ciência subjacente nos capítulos de um 


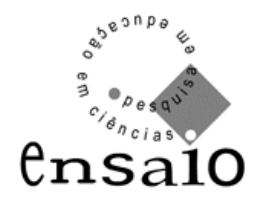

livro didático? A dimensão tácita, pouco discutida na análise do livro didático, representa uma lacuna nas pesquisas epistemológicas sobre o livro didático.

Essa reflexão sobre as dimensões (explícitas e implícitas) da epistemologia na didática da ciência necessita de um procedimento metodológico que possibilitará coletar dados, buscar evidências que permitirão discutir os resultados empíricos e suas respectivas decorrências pedagógicas.

\subsection{A busca por indícios: as marcas textuais.}

Para contornar as dificuldades do método holístico de análise do livro didático, optamos por um desenho metodológico distinto, apresentado por Silva et al. (2005, 2007). A idéia geral é que a categorização do livro será uma inferência baseada em evidências (MISLEVY, 1996). Para isso, nossa unidade de análise não será o livro tomado como uma obra integral e indivisível. Nossa unidade de análise será o livro tomado como um texto que pode ser dividido em fragmentos menores de diversas naturezas, mas fragmentos semânticos. Do ponto de vista de formatação, consideramos que um "fragmento semântico" pode ter mais de um parágrafo. Ele pode conter além do texto, uma fórmula, uma equação. Uma figura e sua legenda do ponto de vista semântico também formam um único fragmento.

Esses fragmentos serão categorizados segundo o conjunto de "marcas textuais" que apresentam. Estamos chamando de "marcas textuais" os indícios textuais que nos permitem identificar as diferentes posturas epistemológicas que estão sendo consideradas para a análise dos livros escolhidos para estudo.

As "marcas textuais" serão, para nós, indícios objetivos, no livro didático, da presença de uma determinada postura epistemológica. Ou seja, cada postura epistemológica utilizada, conscientemente ou não, deixará "marcas", que poderão ser reconhecidas, mapeadas e classificadas.

Em um texto didático, podemos encontrar "marcas textuais" como o uso de certas palavras, expressões, frases e referências explícitas a processos ou procedimentos metodológicos, dentre outras, que nos remetem a uma postura epistemológica do livro, isto é, que se relacionam com os quadros de descritores apresentados anteriormente. Essas marcas textuais podem ser identificadas no texto, 


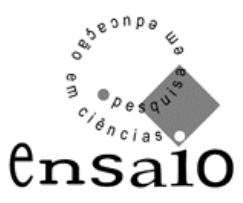

nas citações, nos diagramas, nos exemplos, nas analogias, nos experimentos propostos, bem como nos exercícios.

Como todo dado, a identificação das marcas textuais é um processo de coleta de dados e, portanto, também é um processo dependente das perspectivas do pesquisador. No entanto, esse processo pode ser validado se o conjunto de marcas for submetido a especialista em epistemologia e se ele acorda que elas são realmente marcas que sinalizam claramente uma opção ou postura epistemológica.

\section{PROCEDIMENTOS METODOLÓGICOS}

\subsection{O desenho metodológico}

Nosso desafio é utilizar um procedimento metodológico rigoroso para promover a validação intercodificadores. $O$ desenho apresentado por Silva et al. $(2005,2007)$ é baseado na recursividade do procedimento de validação. Segundo eles, o processo de validação envolve diversos passos: I - segmentação do texto, II - criação de um livro de código, III - codificação, IV -teste da confiabilidade, V - modificação do livro de código.

Os autores indicam dois procedimentos de validação. No primeiro, o livro de código será submetido à concordância intercodificadores. Esses passos são repetidos até que um nível ótimo de confiabilidade intercodificadores (regulados pelo cálculo do coeficiente kappa de Cohen, 1960) seja alcançado.

No segundo procedimento, deve ser efetivada a validação por especialista em epistemologia. O objetivo é verificar se as marcas textuais, depois de serem refinadas pelo processo recursivo de concordância intercodificadores, ainda representam índices de cada uma das duas posturas epistemológicas construídas a partir dos referenciais teóricos considerados.

Assim, a recursividade durante o processo de validação efetiva o refinamento de cada categoria até que obtenha "estabilidade", que representa a confiabilidade do Livro-de-Códigos construído.

Após isso, procede-se à codificação final. O quadro 1 apresenta um diagrama do processo de validação. 


\section{$e^{b^{2 n} p_{\theta}} \varepsilon$ \\ ensa10}

Quadro 1 - Diagrama das etapas da pesquisa

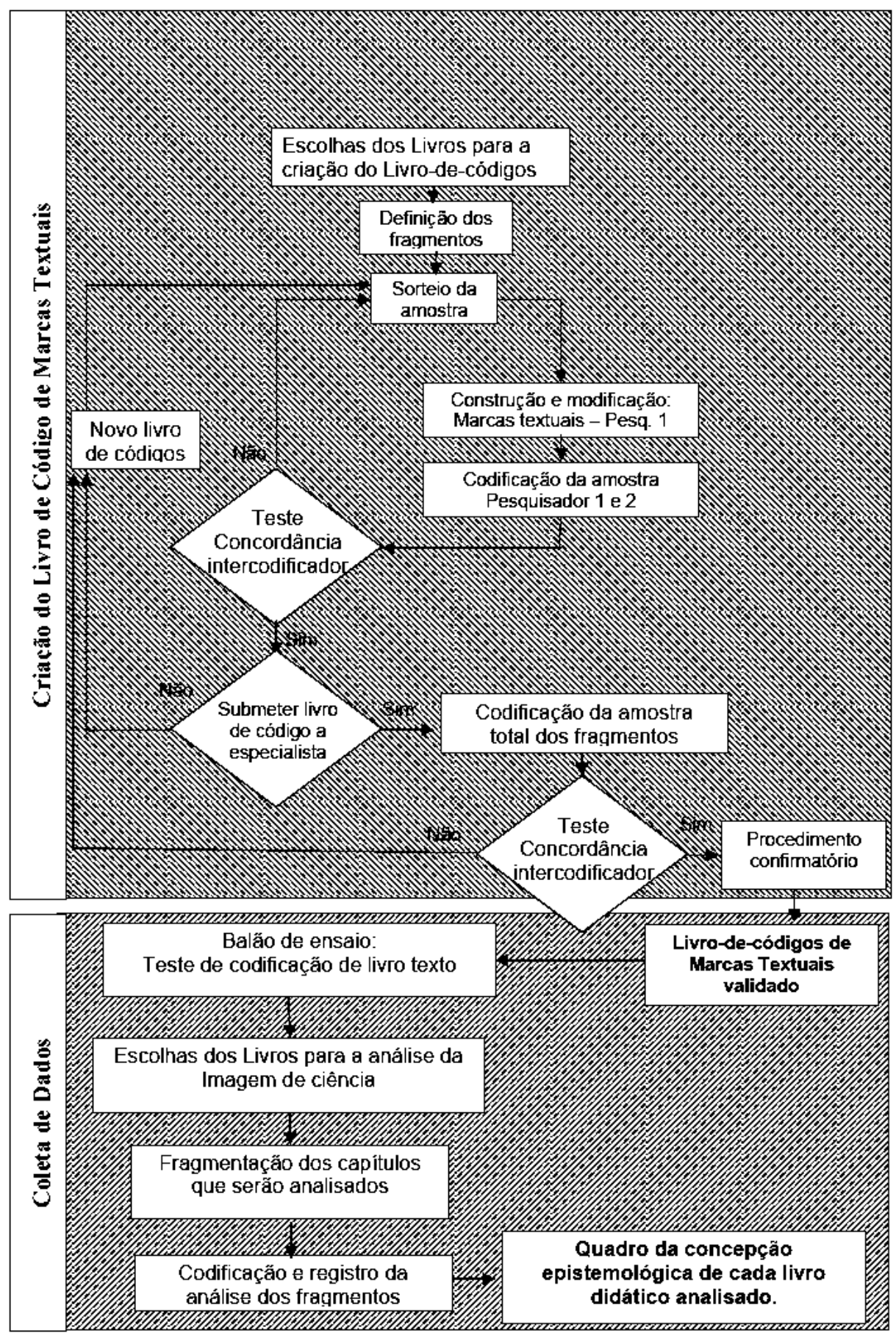

\section{RESULTADOS E DISCUSSÕES}

Apresentaremos resultados de dois processos desse desenho metodológico: a construção de um Livro-de-Códigos de Marcas Textuais e a classificação da imagem de ciência em livros didáticos. 


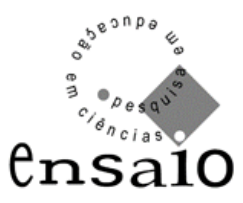

a) O Livro-de-Códigos de Marcas Textuais

O primeiro resultado foi a construção do Livro-de-Códigos de Marcas Textuais. Esse Livro foi construído a partir de descritores de marcas textuais de modo que o pesquisador-codificador possa reconhecê-las em um determinado fragmento.

O primeiro passo para criação do Livro-de-Códigos foi a escolha dos livros didáticos claramente alinhados aos perfis epistemológicos propostos. Os livros escolhidos para a construção dos descritores foram denominados de A (empirista/indutivista) e B (racionalista/dedutivista).

Selecionamos, em cada um dos livros, um capítulo no qual a natureza da ciência (métodos, história, relação com a sociedade e a tecnologia) era abordada explicitamente (em geral, este assunto aparece nos capítulos iniciais, em que o autor apresenta o que é a ciência e o porquê de seu estudo). Escolhemos também o capítulo sobre Eletroquímica (pilhas em particular), no qual, comumente, aparece uma abordagem da história da ciência relacionada aos trabalhos de Volta e Daniell (é comum que os autores apresentem, neste capítulo, alguma relação entre a ciência, a tecnologia e a sociedade).

A partir do estudo dos capítulos dos Livros A e B, bem como da literatura sobre perfil epistemológico (CAMPOS; CHACHAPUZ, 1997), o Livro-de-Códigos inicial foi construído como apresentado no quadro 2.

Quadro 2- Livro-de-Códigos de Descritores das Marcas Textuais (SILVA \& MARTINS, 2007).

\begin{tabular}{|c|c|c|c|c|}
\hline & \multicolumn{4}{|c|}{ DESCRITORES DE MARCAS TEXTUAIS } \\
\hline & $\mathbf{N}^{\mathbf{0}}$ & 1. Empirista/Indutivista & $\mathbf{N}^{\mathbf{0}}$ & 2. Racionalista/Dedutivista \\
\hline 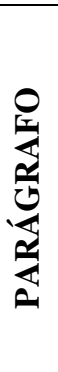 & $\underset{\sim}{\underset{\Omega}{\alpha}}$ & $\begin{array}{l}\text { Método científico a partir de passos iniciados pela } \\
\text { observação (observação - generalização -hipótese - } \\
\text { experiência - resultado - conclusão). Dados são fatos } \\
\text { observados qualitativos ou quantitativos. Leis são } \\
\text { afirmações simples (qualitativas ou matemáticas) que } \\
\text { condensam ou descrevem, por indução, uma série de fatos } \\
\text { isolados. Princípios como generalizações propostas para } \\
\text { explicar observações. Reduzir uma grande série de fatos a } \\
\text { alguns poucos princípios. Teoria é uma explicação do } \\
\text { comportamento observado por meio de um modelo } \\
\text { simples. }\end{array}$ & $\underset{\sim}{\sim}$ & $\begin{array}{l}\text { Teorias e modelos para elaborar hipóteses a partir } \\
\text { de problemas e desenvolvido como “ciclo” sem um } \\
\text { ponto obrigatório de início. A hipótese é uma } \\
\text { explicação provisória de um fenômeno estudado } \\
\text { Busca produzir explicações (teorias ou modelos) } \\
\text { sobre os fenômenos. As observações são definidas } \\
\text { segundo critérios especificados pelas teorias e } \\
\text { modelos. Leis são proposições podendo ser } \\
\text { deduzidas de teorias. Teorias são criações } \\
\text { intelectuais (representações temporárias) do homem } \\
\text { para a explicação dos fenômenos. }\end{array}$ \\
\hline
\end{tabular}




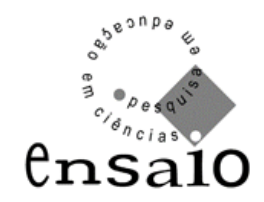

\begin{tabular}{|c|c|c|c|}
\hline$\underset{\sim}{\mathfrak{N}}$ & $\begin{array}{l}\text { A história da ciência não existe ou é apresentada com } \\
\text { caráter formal, linear, crescente e descontextualizada. } \\
\text { Ciência como resultado de um processo de acumulação. } \\
\text { Conceitos científicos cada vez mais próximos da verdade. } \\
\text { A ciência é uma busca da verdade, por isso suas teorias e } \\
\text { princípios são a-históricos. Apresentam pequenas } \\
\text { biografias indicando datas relativas a cientistas isolados, } \\
\text { descobertas e pequenos episódios históricos } \\
\text { descontextualizados. Trabalho científico apresentado } \\
\text { como obra de cientistas isolados e intelectualmente } \\
\text { geniais. }\end{array}$ & 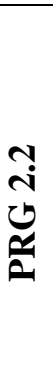 & $\begin{array}{l}\text { Aproveita períodos de controvérsias para mostrar a } \\
\text { evolução dos conceitos. Mostra a evolução dos } \\
\text { conceitos e teorias a partir de dúvidas e erros. } \\
\text { Apresenta as limitações na construção dos } \\
\text { conhecimentos científicos. As teorias são criações } \\
\text { intelectuais e dependem de fatores como: época } \\
\text { histórica, fatores ideológicos, criatividade do } \\
\text { cientista. Apresenta o cientista inserido em uma } \\
\text { comunidade científica que participa e valida as } \\
\text { descobertas. Apresentam o conhecimento científico } \\
\text { como intercâmbio e competitividade entre equipes } \\
\text { de investigação científica. }\end{array}$ \\
\hline 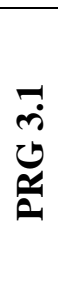 & $\begin{array}{l}\text { Apresenta o conhecimento científico sem levar em conta o } \\
\text { uso da ciência/tecnologia no dia-a-dia. O uso de regras } \\
\text { como forma de aplicar esse conhecimento. Conhecimento } \\
\text { científico como um conjunto de fatos, leis e teorias que } \\
\text { valem por si mesmos. Geralmente não recorre a contextos } \\
\text { sociais ou científicos que são relacionados aos conceitos, a } \\
\text { não ser como meros exemplos. Tecnologia é decorrência } \\
\text { da ciência. }\end{array}$ & $\underset{\substack{n\\
}}{\mathfrak{n}}$ & $\begin{array}{l}\text { Parte de problemas sociais ou tecnológicos para } \\
\text { introduzir conceitos e teorias. Apresenta temas } \\
\text { desenvolvidos em um contexto com relevância social, } \\
\text { científica ou tecnológica. Mostra as implicações da } \\
\text { ciência/tecnologia sobre } \\
\text { homem/ambiente/patrimônio e a sociedade em geral. } \\
\text { Tecnologia como campo próprio, porém, interligada } \\
\text { à ciência. }\end{array}$ \\
\hline 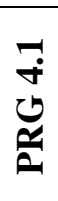 & $\begin{array}{l}\text { Ciência e tecnologia como fator absoluto de progresso. } \\
\text { Capacidade quase ilimitada de resolver problemas que se } \\
\text { impõem à humanidade. Ignoram-se as implicações sociais } \\
\text { da ciência e da tecnologia. Ignora-se a influência da } \\
\text { sociedade no desenvolvimento da ciência e tecnologia. }\end{array}$ & 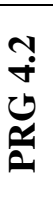 & $\begin{array}{l}\text { Ciência e tecnologia em evolução, mas enfatiza } \\
\text { limitações, erros e dúvidas. Ciência e tecnologia } \\
\text { como fonte de problemas e soluções. Realçam as } \\
\text { interações entre ciência, tecnologia e sociedade. } \\
\text { Mostra-se que a ciência e a tecnologia influenciam e } \\
\text { são influenciadas pela sociedade. }\end{array}$ \\
\hline
\end{tabular}

\begin{tabular}{|c|c|c|c|c|}
\hline & $\mathbf{N}^{\mathbf{0}}$ & 1. Empirista/Indutivista & $\mathbf{N}^{\mathbf{0}}$ & 2. Racionalista/Dedutivista \\
\hline 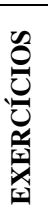 & 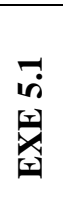 & $\begin{array}{l}\text { Exercícios propostos aos alunos são esquematizados } \\
\text { segundo a sequência dos “passos” do método } \\
\text { científico. Exercícios são desenvolvidos como } \\
\text { aplicação de um determinado princípio, teoria ou } \\
\text { formulação. }\end{array}$ & 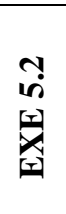 & $\begin{array}{l}\text { Propõem-se aos alunos atividades diversificadas, } \\
\text { desde o planejamento à execução de experiências } \\
\text { para questionar ideias dos alunos ou do livro } \\
\text { didático. São desenvolvidos a partir de uma situação- } \\
\text { problema em função de um contexto social ou } \\
\text { científico. }\end{array}$ \\
\hline 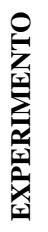 & $\begin{array}{l}-1 \\
\dot{b} \\
2 \\
x \\
1\end{array}$ & $\begin{array}{l}\text { Experimentos propostos seguindo os "passos" do } \\
\text { “método científico". Experimento para demonstrar } \\
\text { a validade de determinado princípio, aspecto } \\
\text { teórico ou fórmula já apresentada anteriormente. }\end{array}$ & 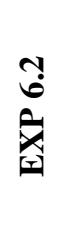 & $\begin{array}{l}\text { Experimentos visando a explorar um } \\
\text { determinado fenômeno. Experimento com } \\
\text { caráter reflexivo para desenvolver estratégias e } \\
\text { hipóteses para resolução de problemas. }\end{array}$ \\
\hline 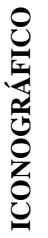 & 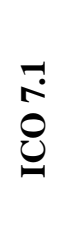 & $\begin{array}{l}\text { Esquema de um processo aparecendo na legenda } \\
\text { como o “modo" ou a maneira pela qual tal } \\
\text { fenômeno acontece. Foto ou desenho como se fosse a } \\
\text { “demonstração real” de um mecanismo ou de uma } \\
\text { teoria. }\end{array}$ & 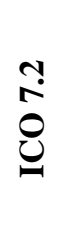 & $\begin{array}{l}\text { Esquema de um processo indicando na legenda } \\
\text { como "modelo" ou possível "representação" de } \\
\text { como o fenômeno acontece. Foto ou desenho } \\
\text { como suposição a partir de um determinado } \\
\text { modelo ou abordagem. }\end{array}$ \\
\hline
\end{tabular}

Esse Livro-de-Códigos apresenta quatro tipos de marcas textuais classificadas em quatro subtipos para parágrafos (PRG), um tipo de descritores para exercícios (EXE), um tipo de marcas para experimento (EXP) e um tipo de descritores para fragmento iconográfico (ICO), isto é, fotos, esquemas ou desenhos que apresentam, com sua legenda, certa independência no livro didático. 


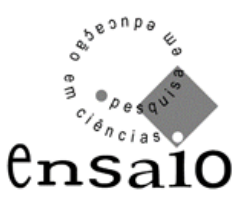

Os parágrafos (PRG) apresentam maior diversidade de descritores devido a temas relativos à descrição da ciência ( $1^{\circ}$ subtipo), a história da ciência ( $2^{\circ}$ subtipo), à apresentação do conteúdo ( $3^{\circ}$ subtipo) e a relação ciência, tecnologia e sociedade $\left(4^{\circ}\right.$ subtipo).

Quadro 3 - Exemplos de algumas categorias de parágrafos.

\begin{tabular}{|c|c|c|}
\hline $\mathrm{N}^{\mathrm{o}}$ & 1. Empirista/Indutivista & 2. Racionalista/Dedutivista \\
\hline & $\begin{array}{l}\text { A ciência começa pela observação. Chamam-se dados os } \\
\text { fatos observados, sejam eles qualitativos ou } \\
\text { quantitativos. Assim, as descrições feitas anteriormente } \\
\text { sobre o comportamento de água, hidrogênio e oxigênio } \\
\text { são exemplos de dados. Através dos anos, os dados } \\
\text { acumulados alcançaram uma proporção fabulosa, mas } \\
\text { mesmo assim um químico deve ter um bom } \\
\text { conhecimento de grande parte deles. É praticamente } \\
\text { impossível rememorar tantos dados como fatos isolados; } \\
\text { felizmente, a grande maioria deles pode ser condensadas } \\
\text { em afirmações simples e resumidas. Tais afirmações, que } \\
\text { descrevem o comportamento geral da natureza, são } \\
\text { chamadas leis. (SP p 13) }\end{array}$ & $\begin{array}{l}\text { Observe que o método científico é um } \\
\text { ciclo e, assim sendo, constitui um } \\
\text { esquema flexível, sem ponto } \\
\text { predeterminado para começar e } \\
\text { terminar. Veremos a seguir os principais } \\
\text { aspectos desse ciclo. (ALp13) }\end{array}$ \\
\hline & $\begin{array}{l}\text { O estudo da química nos dá urna compreensão dos } \\
\text { processos de raciocínio usados em ciência. Como qualquer } \\
\text { outro cientista, o químico procura reduzir uma grande } \\
\text { série de fatos observados a alguns poucos princípios } \\
\text { gerais. O objetivo principal da pesquisa científica é } \\
\text { estabelecer tais princípios, que devem explicar todos os } \\
\text { fatos experimentais observados, possibilitar a organização } \\
\text { sistemática do conhecimento e prever o comportamento } \\
\text { em situações novas. É importante lembrar que esses } \\
\text { princípios só são válidos com base nos fatos experimentais } \\
\text { que lhes deram origem. (SP p 4) }\end{array}$ & $\begin{array}{l}\text { Tudo o que ocorre na natureza é } \\
\text { chamado de fenômeno. A chama de uma } \\
\text { vela, o som de um violão ou o } \\
\text { movimento do Sol são exemplos de } \\
\text { fenômenos. } \\
\text { Quando o cientista consegue uma boa } \\
\text { explicação para o fenômeno observado, } \\
\text { ele está criando uma teoria. As teorias } \\
\text { são as principais alavancas no avanço de } \\
\text { uma ciência. (ALp14) }\end{array}$ \\
\hline
\end{tabular}

Cada subtipo apresenta um descritor para o perfil 1 (empirista/indutivista) e outro para o perfil 2 (racionalista/dedutivista).

É importante frisar que são dimensões epistemológicas, isto é, representam posturas epistemológicas distintas, que evidentemente correspondem a consequências pedagógicas distintas, mas que servem de referencial para enquadramento (mapeamento) de visões apresentadas em um determinado livro didático.

\section{b) Classificando um livro didático por meio do Livro-de-Códigos}

Apresentamos a análise, a partir do Livro-de-Códigos de Marcas Textuais, de um livro didático escolhido por constar do Programa de Avaliação do Livro Didático para o Ensino Médio (PNLEM-2007), além de constar como um dos livros mais requisitados pelos professores em escolas públicas e particulares. O objetivo dessa 


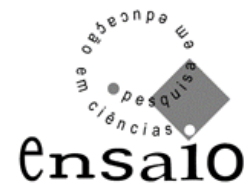

análise é avaliar os procedimentos metodológicos apresentados como ferramenta para a investigação epistemológica.

O livro escolhido foi denominado de L2. Foram fragmentados os capítulos introdutórios (INTRO), pilhas (PILHAS) e, de forma aleatória, foi definido um terceiro capítulo, no caso, a radioatividade (RADIO). O terceiro capítulo cumpre o papel de diminuir o viés do pesquisador e, portanto, servir de triangulação e de procedimento confirmatório para a análise do livro didático. Os capítulos dos livros foram fragmentados e classificados segundo as marcas textuais categorizadas.

No quadro 4, apresentamos a quantidade de fragmentos codificados, o número de marcas textuais, tanto no total como em cada tipo e subtipo de descritores de marcas textuais, conforme quadro de descritores apresentado anteriormente (quadro 2). Aparecem as marcas identificadas no perfil epistemológico 1 (empirista/indutivista), indicadas como perfil 1, e as marcas identificadas com o perfil epistemológico 2 (racionalista/dedutivista).

No L2, em um total de 346 fragmentos codificados, 338 (97,7\%) apresentam marcas textuais. Desse total, $168(49,7 \%$ das marcas $)$ apresentam perfil epistemológico 1, enquanto $170 \quad(50,3 \%$ das marcas $)$ apresentam perfil epistemológico 2. Além disso, praticamente, quase todos os tipos de marcas textuais apareceram.

O quadro 4, apresentado a seguir, mostra o resultado da categorização dos fragmentos segundo o reconhecimento das marcas textuais, para cada livro didático escolhido. 


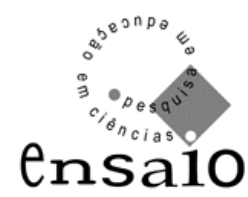

Quadro 4 - Marcas textuais identificadas em L2 (SILVA; MARTINS, 2007).

\begin{tabular}{|c|c|c|c|c|c|c|c|c|c|c|}
\hline \multirow{4}{*}{\multicolumn{2}{|c|}{$\begin{array}{l}\text { MARCAS } \\
\text { TEXTUAIS }\end{array}$}} & \multicolumn{9}{|c|}{ LIVRO L2 } \\
\hline & & \multicolumn{8}{|c|}{ Perfil epistemológico } & \multirow[b]{3}{*}{ TOTAL } \\
\hline & & \multicolumn{2}{|c|}{ INTRO } & \multicolumn{2}{|c|}{ PILHAS } & \multicolumn{2}{|c|}{ RADIO } & \multicolumn{2}{|c|}{ total L2 } & \\
\hline & & 1 & 2 & 1 & 2 & 1 & 2 & totall & total2 & \\
\hline \multirow[b]{5}{*}{ PRG } & 1 & 1 & 0 & 0 & 0 & 0 & 0 & 1 & 0 & 1 \\
\hline & 2 & 6 & 5 & 1 & 7 & 3 & 11 & 10 & 23 & 33 \\
\hline & 3 & 23 & 12 & 20 & 18 & 10 & 33 & 53 & 63 & 116 \\
\hline & 4 & 1 & 11 & 0 & 17 & 0 & 16 & 1 & 44 & 45 \\
\hline & subtotal & 31 & 28 & 21 & 42 & 13 & 60 & 65 & 130 & 195 \\
\hline EXE & 5 & 22 & 13 & 35 & 11 & 30 & 6 & 87 & 30 & 117 \\
\hline EXP & 6 & 2 & 0 & 1 & $\mathbf{0}$ & $\mathbf{0}$ & 0 & 3 & 0 & 3 \\
\hline ICO & 7 & 9 & 3 & 2 & 2 & 2 & 5 & 13 & 10 & 23 \\
\hline \multicolumn{2}{|c|}{$\begin{array}{c}\text { Totais marcas } \\
\text { por perfil }\end{array}$} & 64 & 44 & 59 & 55 & 45 & 71 & 168 & 170 & 338 \\
\hline \multicolumn{2}{|c|}{$\begin{array}{c}\% \text { marcas por } \\
\text { perfil }\end{array}$} & 59,3 & 40,7 & 51,8 & 48,2 & 38.8 & 61,2 & 49,7 & 50,3 & 100,0 \\
\hline \multicolumn{2}{|c|}{$\begin{array}{l}\text { Totais marcas } \\
\text { por capítulo }\end{array}$} & \multicolumn{2}{|c|}{108} & \multicolumn{2}{|c|}{114} & \multicolumn{2}{|c|}{116} & \multicolumn{2}{|c|}{338} & 338 \\
\hline \multicolumn{2}{|c|}{$\begin{array}{l}\% \text { marcas por } \\
\text { capitulo }\end{array}$} & \multicolumn{2}{|c|}{100,0} & \multicolumn{2}{|c|}{98,3} & \multicolumn{2}{|c|}{95,1} & \multicolumn{2}{|c|}{97,7} & 97,7 \\
\hline \multicolumn{2}{|c|}{$\begin{array}{c}\text { TOTAL } \\
\text { FRAGMENTOS }\end{array}$} & \multicolumn{2}{|c|}{108} & \multicolumn{2}{|c|}{116} & \multicolumn{2}{|c|}{122} & \multicolumn{2}{|c|}{346} & 346 \\
\hline \multicolumn{2}{|c|}{$\begin{array}{l}\text { Sem marcas } \\
\text { identificadas }\end{array}$} & \multicolumn{2}{|c|}{0} & \multicolumn{2}{|c|}{2} & \multicolumn{2}{|c|}{6} & \multicolumn{2}{|c|}{8} & 8 \\
\hline \multicolumn{2}{|c|}{$\begin{array}{c}\% \text { total de } \\
\text { marcas }\end{array}$} & \multicolumn{2}{|c|}{100,0} & \multicolumn{2}{|c|}{98,3} & & & & & 97,7 \\
\hline
\end{tabular}

As marcas não só permitem a definição de um perfil epistemológico como também permitem analisar as características particulares de um livro didático, pois quanto mais marcas são percebidas, maior será a riqueza da abordagem utilizada. Esses resultados indicam a acuidade da ferramenta metodológica utilizada para o estudo epistemológico de um livro didático ${ }^{1}$.

\subsection{Epistemologia tácita e explícita nos parágrafos, exercícios, experimentos e} fragmentos iconográficos.

O quadro 5 abaixo apresenta os resultados obtidos a partir da categorização dos fragmentos coletados.

\footnotetext{
${ }^{1}$ Na dissertação "A epistemologia-em-uso: Imagem de ciência nos livros didáticos de Química" (SILVA; MARTINS, 2007) é feita a análise e a discussão de todos os aspectos principais sobre o estudo epistemológico de três livros didáticos.
} 


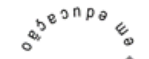 \\ $\exists \oplus^{\circ}$ \\ ensa10}

Quadro 5 - Tabela com valores e percentagens dos tipos de fragmentos analisados.

\begin{tabular}{|c|c|c|c|c|c|c|c|c|c|}
\hline & \multicolumn{2}{|c|}{ INTRO } & \multicolumn{2}{|c|}{ PILHAS } & \multicolumn{2}{|c|}{ RADIO } & \multicolumn{2}{|c|}{ parcial } & \multirow{2}{*}{ total } \\
\hline & 1 & 2 & 1 & 2 & 1 & 2 & 1 & 2 & \\
\hline PRG 01 & $\begin{array}{c}1 \\
(100 \%)\end{array}$ & 0 & 0 & 0 & 0 & 0 & $\begin{array}{c}1 \\
(100 \%)\end{array}$ & 0 & $\begin{array}{c}1 \\
(0,3 \%)\end{array}$ \\
\hline PRG 02 & $\begin{array}{c}6 \\
(54,5 \%)\end{array}$ & $\begin{array}{c}5 \\
(45,5 \%)\end{array}$ & $\begin{array}{c}1 \\
(12,5 \%)\end{array}$ & $\begin{array}{c}7 \\
(87,5 \%)\end{array}$ & $\begin{array}{c}3 \\
(21,4 \%)\end{array}$ & $\begin{array}{c}11 \\
(78,6 \%)\end{array}$ & $\begin{array}{c}10 \\
(30,3 \%)\end{array}$ & $\begin{array}{c}23 \\
(69,7 \%)\end{array}$ & $\begin{array}{c}33 \\
(9,8 \%)\end{array}$ \\
\hline PRG 03 & $\begin{array}{c}23 \\
(65,7 \%) \\
\end{array}$ & $\begin{array}{c}12 \\
(34,3 \%) \\
\end{array}$ & $\begin{array}{c}20 \\
(52,6 \%) \\
\end{array}$ & $\begin{array}{c}18 \\
(47,4 \%) \\
\end{array}$ & $\begin{array}{c}10 \\
(23,2 \%) \\
\end{array}$ & $\begin{array}{c}33 \\
(76,8 \%) \\
\end{array}$ & $\begin{array}{c}53 \\
(45,7 \%) \\
\end{array}$ & $\begin{array}{c}63 \\
(54,3 \%) \\
\end{array}$ & $\begin{array}{c}116 \\
(34,3 \%) \\
\end{array}$ \\
\hline PRG 04 & $\begin{array}{c}1 \\
(5,8 \%)\end{array}$ & $\begin{array}{c}11 \\
(94,2 \%)\end{array}$ & 0 & $\begin{array}{c}17 \\
(100 \%) \\
\end{array}$ & 0 & $\begin{array}{c}16 \\
(100 \%)\end{array}$ & $\begin{array}{c}1 \\
(2,2 \%)\end{array}$ & $\begin{array}{c}44 \\
(97,8 \%)\end{array}$ & $\begin{array}{c}45 \\
(13,3 \%) \\
\end{array}$ \\
\hline $\begin{array}{l}\text { Total } \\
\text { PRG }\end{array}$ & $\begin{array}{c}31 \\
(52,5 \%) \\
\end{array}$ & $\begin{array}{c}28 \\
(47,5 \%) \\
\end{array}$ & $\begin{array}{c}21 \\
(33,3 \%) \\
\end{array}$ & $\begin{array}{c}42 \\
(66,7 \%) \\
\end{array}$ & $\begin{array}{c}13 \\
(17,8 \%) \\
\end{array}$ & $\begin{array}{c}60 \\
(82,2 \%) \\
\end{array}$ & $\begin{array}{c}65 \\
(33,3 \%) \\
\end{array}$ & $\begin{array}{c}130 \\
(66,7 \%) \\
\end{array}$ & $\begin{array}{c}195 \\
(57,7 \%) \\
\end{array}$ \\
\hline EXE & $\begin{array}{c}22 \\
(62,9 \%) \\
\end{array}$ & $\begin{array}{c}13 \\
(37,1 \%) \\
\end{array}$ & $\begin{array}{c}35 \\
(76,1 \%) \\
\end{array}$ & $\begin{array}{c}11 \\
(23,9 \%)\end{array}$ & $\begin{array}{c}30 \\
(83,3) \\
\end{array}$ & $\begin{array}{c}6 \\
(16,7 \%) \\
\end{array}$ & $\begin{array}{c}87 \\
(74,4 \%) \\
\end{array}$ & $\begin{array}{c}30 \\
(15,6 \%) \\
\end{array}$ & $\begin{array}{c}117 \\
(34,6 \%) \\
\end{array}$ \\
\hline EXP & $\begin{array}{c}2 \\
(100 \%)\end{array}$ & 0 & $\begin{array}{c}1 \\
(100 \%)\end{array}$ & 0 & 0 & 0 & $\begin{array}{c}3 \\
(100 \%)\end{array}$ & 0 & $\begin{array}{c}3 \\
(0,9 \%) \\
\end{array}$ \\
\hline ICO & $\begin{array}{c}9 \\
(75 \%) \\
\end{array}$ & $\begin{array}{c}3 \\
(25 \%) \\
\end{array}$ & $\begin{array}{c}2 \\
(50 \%) \\
\end{array}$ & $\begin{array}{c}2 \\
(50 \%) \\
\end{array}$ & $\begin{array}{c}2 \\
(28,6 \%) \\
\end{array}$ & $\begin{array}{c}5 \\
(71,4 \%) \\
\end{array}$ & $\begin{array}{c}13 \\
(56,5 \%) \\
\end{array}$ & $\begin{array}{c}10 \\
(43,5 \%) \\
\end{array}$ & $\begin{array}{c}23 \\
(6,8 \%) \\
\end{array}$ \\
\hline $\begin{array}{l}\text { Total } \\
\text { Livro } \\
\end{array}$ & $\begin{array}{c}64 \\
(59,3 \%)\end{array}$ & $\begin{array}{c}44 \\
(40,7 \%)\end{array}$ & $\begin{array}{c}59 \\
(51,8 \%) \\
\end{array}$ & $\begin{array}{c}55 \\
(48,2 \%) \\
\end{array}$ & $\begin{array}{c}45 \\
(49,7 \%)\end{array}$ & $\begin{array}{c}71 \\
(61,2 \%) \\
\end{array}$ & $\begin{array}{c}168 \\
(49,7 \%) \\
\end{array}$ & $\begin{array}{c}170 \\
(50,3 \%)\end{array}$ & 338 \\
\hline
\end{tabular}

Observa-se, no capítulo Introdutório, que a diferença de percentual entre os perfis epistemológicos $(59,3 \%-40,7 \%=18,6 \%)$ é superior ao $\Delta \mathrm{P}^{2}$ calculado $(9,3 \%)$, portanto nesse capítulo o predomínio do perfil empirista (1) é significativo. No capítulo Pilhas, a diferença de percentual entre os perfis $(3,6 \%)$ é inferior ao $\Delta \mathrm{P}$ calculado $(9,1 \%)$ não existindo, portanto, nenhuma predominância significativa. Por sua vez, no capítulo Radioatividade, a diferença percentual entre os perfis (11,5\%) é superior ao $\Delta \mathrm{P}$ calculado (8,9\%), o que permite identificar o predomínio do perfil racionalista (2) nesse capítulo. Considerando o total de fragmentos dos capítulos analisados não foram encontradas diferenças significativas no percentual de marcas. A diferença de percentual entre os perfis é muito inferior ao $\Delta \mathrm{P}$ calculado $(5,3 \%)$. Desse modo, pode-se considerar que, no Livro 2, há um equilíbrio entre os perfis epistemológicos identificados no conjunto dos capítulos analisados.

Ao analisar os capítulos codificados, é possível perceber que existe uma diferença entre o "apelo tecnológico" que apresentam. O capítulo Radioatividade tem um apelo tecnológico maior que o capítulo Pilhas. Este, por sua vez, tem um apelo tecnológico maior que o capítulo Introdutório. O interessante, no livro L2, é que

\footnotetext{
${ }^{2} \mathrm{O}$ valor estatístico para significância é calculado, pelo Método Clássico de Teste de Hipótese, a partir dos valores de variação (desvios) $(\Delta \mathrm{P})$ considerando o grau de confiança igual a $95 \%(\alpha=0,05$ e $\mathrm{z}=1,96)$, conforme TRIOLA, 1999, p.192/193 e 228/230.
} 


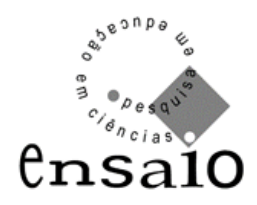

quanto maior o apelo tecnológico que o capítulo apresenta, maior o percentual do perfil 2 identificado (INTRO - 40,7\%; PILHAS - 48,2\%; RADIO - 61,2\%). Observase também que essas diferenças são significativas, pois ultrapassam o $\Delta \mathrm{P}$ calculado, por exemplo, a diferença entre os percentuais do perfil 2 entre o capítulo Introdutório e o de Pilhas $(7,5 \%)$ é superior ao $\Delta \mathrm{P}$ calculado $(1,3 \%)$ para proporção entre os fragmentos dos dois capítulos. Isso também acontece com as diferenças de marcas epistemológicas 2 entre os demais capítulos. Por outro lado, contraditoriamente, quando maior o perfil 2 nos parágrafos dos capítulos analisados menor é a proporção do perfil 1 nos exercícios apresentados nesses capítulos.

Um capítulo como radioatividade não tem um conteúdo de química muito específico (afinal não trata de uma reação química convencional) e acaba descrevendo a questão das bombas atômicas ou de hidrogênio, a aplicação da radioatividade na medicina, na conservação dos alimentos, obtenção de energia elétrica por reatores nucleares, etc. Isso nos levanta a suspeita de que esse apelo tecnológico pode induzir os autores a explorarem a relação entre ciência, tecnologia e sociedade bem mais do que o usual. Por sua vez, um capítulo como o de Pilhas apresenta vários aspectos tecnológicos (o uso de pilhas e baterias, as variedades de pilhas, se são recarregáveis ou não, o descarte dessas pilhas, etc.), mas os conteúdos químicos específicos são mais identificados e desenvolvidos (a óxi-redução, a corrosão e a deposição metálica, o potencial de redução, a diferença de potencial, etc.). Assim, nesse capítulo, o apelo para a relação ciência, tecnologia e sociedade fica com menor intensidade. Já o capítulo Introdutório apresenta marcas textuais tipo parágrafo com a maior incidência do perfil 1 (Intro - 52,5\%; Pilhas - 33,3\% e Radio - 17,8\%). Além de o capítulo Introdutório apresentar um menor apelo tecnológico, aparentemente os autores ficaram mais preocupados em tratar de conteúdos básicos. Pode-se observar que esse capítulo quase não descreve a natureza da ciência e do conhecimento científico (existe apenas um fragmento dessa categoria) e é o capítulo que menos utiliza a descrição da relação ciência, tecnologia e sociedade (12 fragmentos é a menor freqüência dessa categoria nos capítulos analisados).

Outra característica interessante sobre o livro L2 é que, nas marcas tipo parágrafo (PRG), o perfil 2 predomina $(66,7 \%)$, enquanto nos outros tipos de fragmentos (EXE, EXP e ICO) predomina o perfil 1 (72\%). Isso pode indicar que, na 


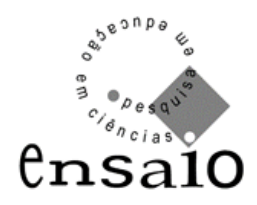

construção da narrativa para apresentar os conteúdos, mesmo nos mais específicos da química, existe a preocupação com a contextualização, seja a partir da relação ciência, tecnologia e a sociedade ou com a história da ciência. Afinal, de todas as marcas textuais encontradas, em 34,3\% o conhecimento científico é apresentado, 9,8\% descrevem a relação ciência, tecnologia e sociedade e 13,3\% abordam a descrição da história da ciência. Estas marcas superam significativamente aquelas relativas à descrição da natureza da ciência $(0,3 \%)$. Porém, essa preocupação desaparece no tratamento dos exercícios $(74,4 \%$ marcas tipo 1$)$, dos experimentos (100\% marcas tipo 1) e dos fragmentos iconográficos (56,5\% marcas tipo 1$)$.

Essas características da narrativa, particularmente apresentando um perfil epistemológico diferente dos outros tipos de fragmentos, podem ser consideradas como indícios da influência das definições oficiais, isto é, podem ser resultado das orientações oficiais, tais como $\mathrm{PCN}, \mathrm{DCN}$ e $\mathrm{OCN}$, que são significativas para a análise do livro didático no PNLD. Esses documentos oficiais defendem a necessidade de que o currículo de química desenvolva reflexões sobre a ciência, tecnologia e sociedade, principalmente visando à contextualização e à interdisciplinaridade (art. $6^{\circ}$ das DCN). As orientações, por sua vez, podem induzir os autores a uma abordagem textual mais próxima do perfil epistemológico 2.

Pode-se perceber isso ao detectar que os fragmentos com marcas textuais sobre ciência, tecnologia e sociedade junto com as marcas tipo história da ciência apresentam $86 \%$ de marcas tipo 2, no entanto as marcas que apresentam o conhecimento (PRG 3) apresentam 54\% com perfil 2, isto é, não têm a predominância desse perfil epistemológico (a diferença não é significativa, pois não supera o $\Delta \mathrm{P}$ calculado - 8,9\%), caindo para 15,6\% nos fragmentos tipo exercício.

As categorias PRG 4 e PRG 2 (descrevem a ciência, tecnologia e sociedade e a história da ciência respectivamente) apresentam uma dimensão epistemológica distinta das demais categorias (sejam ou não parágrafos). Isso pode ser explicado pela possível influência das diretrizes oficiais, podendo, portanto, representar um indício importante do papel dessas diretrizes na elaboração dos livros didáticos. Considera-se que a predominância do perfil 2 em categorias de parágrafos representa, neste livro, um enriquecimento para a abordagem desenvolvida. 


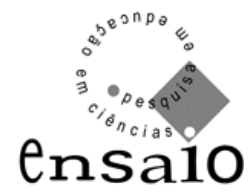

Por outro lado, discutir-se-ão, em outros capítulos, os impactos que os outros tipos de marcas textuais, particularmente as atividades propostas (exercícios), podem produzir no processo pedagógico, devido a apresentarem um perfil epistemológico oposto ao perfil epistemológico apresentado textualmente nos parágrafos. A questão que se coloca para discussão é sobre o impacto dos exercícios na visão do aluno. $\mathrm{O}$ texto didático apresentado pelos autores dos livros necessariamente teria maior relevância do que as atividades propostas para o aluno exercitar seu conhecimento? Suspeita-se que não. Embora atuem vários fatores relevantes sobre o impacto pedagógico, os exercícios poderão desempenhar um papel específico devido à dimensão tácita da epistemologia desenvolvida. A epistemologia-em-uso subjacente aos exercícios poderá exercer um impacto na conceitualização como pode ser discutida a partir dos referenciais indicados (POLANYI, 1983; SCHÖN, 1987; VERGNAUD, 1988).

Nessa percepção, o L2 tem a dimensão do perfil epistemológico 1 e, possivelmente ao tentar responder às orientações oficiais, sua narrativa supera o perfil epistemológico empirista. Isso é observado, por exemplo, nos parágrafos que tratam da relação ciência, tecnologia e sociedade e da história da ciência onde ocorre predominância do perfil epistemológico 2. Mas, no conjunto dos demais tipos de fragmentos na narrativa, como na dimensão epistemológica dos exercícios, dos experimentos e dos fragmentos iconográficos, o perfil empirista predomina.

\section{CONCLUSÕES}

Este trabalho apresentou um desenho metodológico que permitiu identificar como a visão de ciência, a história da ciência, a relação entre tecnologia, ciência e sociedade são apresentadas em um livro didático. A metodologia de validação recursiva transformou-se em uma ferramenta valiosa para efetivar um Livro-deCódigos que permitiu coletar os dados e buscar evidências para as análises pretendidas.

Pudemos não só identificar claramente o tipo epistemológico predominante nos parágrafos, como também nos exercícios, nos experimentos e nos elementos iconográficos presentes no livro didático. 


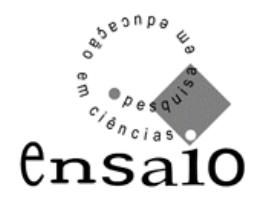

Identificamos evidências sobre a epistemologia verbalizada nas descrições apresentações sobre a ciência no livro didático, como também a epistemologia-emuso, isto é, a epistemologia implícita nos vários tipos de fragmentos semânticos coletados. A comparação entre as duas dimensões epistemológicas permite a necessária reflexão sobre a dimensão tácita da epistemologia no livro didático e suas decorrências pedagógicas. Essa reflexão, poucas vezes abordada, é um elemento novo e relevante nas análises epistemológicas do livro didático.

A metodologia permitiu não só a identificação das características particulares de cada livro didático como também uma reflexão sobre suas implicações pedagógicas, na busca de indícios sobre a real ligação entre a didática da ciência e a epistemologia. Abre a perspectiva de pesquisa sobre como os fragmentos semânticos aparecem na tessitura didática do livro texto, buscando, no concreto do texto, a relação entre a epistemologia e a didática.

Permitiu também, a reflexão sobre como atuar no sentido de buscar políticas de formação dos professores, pois geralmente, muitas pesquisas apontam a necessidade da formação epistemológica, no entanto sem veicular a dimensão epistemológica que pode estar subjacente a cada escolha efetuada pelo professor na seqüência didática escolhida para a sua sala de aula.

A pesquisa abre a perspectiva de discutir, durante a formação do professor, a necessidade da escolha consciente da epistemologia que está subjacente à sua maneira de apresentar do conhecimento científico, dos exercícios que escolheu para propor aos seus alunos, das atividades experimentais escolhidas e preparadas para o desenvolvimento de seus conteúdos.

A coerência entre a teoria explicita e a teoria implícita nas sequências didáticas efetivadas pelo professor poderá ter um alcance mais efetivo na formação de seus alunos.

\section{REFERÊNCIAS BIBLIOGRÁFICAS}

ARGYRIS, C.; SCHÖN, D. A. Theory in Practice - Increasing professional effectiveness. San Francisco: Jossey-Bass, 1974.

ARRUDA, S. M.; SILVA, M. R.; LABURÚ, C. E. Laboratório didático de física a partir de uma perspectiva kuhniana. Investigações em Ensino de Ciências, v.6, n.1, p.97-106, 2001. 


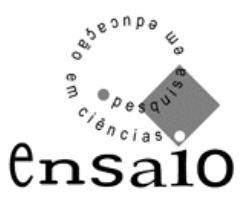

CACHAPUZ, A.; PÉREZ, D. G.; MONTORO, I. F. PRATA, J. Para uma imagem não deformada do trabalho científico. Ciência \& Educação, v.7, n.2, p.125-153, 2001.

CACHAPUZ, A.; PÉREZ, I. F.; Prata, J. A hipótese e a experiência científica em educação em ciência: contributos para uma reorientação epistemológica. Ciência \& Educação, v.8, n.2, p.253-262, 2002.

CACHAPUZ, A. et al. A necessária renovação do ensino de ciências. Cortez: São Paulo. 2005.

CAMPOS, C. CACHAPUZ, A. Imagens de ciência em manuais de química portugueses. Química nova na escola. ${ }^{\circ}$ 6, p.23-29, nov. 1997.

COHEN, J. A coefficient of agreement for nominal scales. Educational and Psychological Measurement, v.20, p.37-46. 1960.

CRONBACH, L. J. Essentials of psychological testing. New York: Harper Collins. 1990.

DELIZOICOV, N. C. O professor de ciências naturais e o livro didático (no ensino de programas de saúde). Dissertação (Mestrado em Educação) - Centro de Ciências da Educação, Universidade Federal de Santa Catarina. Florianópolis, 1995.

EISENHART, M.; DEHAAN, R. L. Doctoral Preparation of Scientifically Based Education Researchers. Educational Researcher, v.34, n.4, p.3-13, may. 2005.

EL-HANI, C. N.; TAVARES, J. M.; ROCHA, P. L. B. Concepções epistemológicas de estudantes de biologia e sua transformação por uma proposta explícita de ensino sobre história e filosofia das ciências. Investigações em Ensino de Ciências. v.9, n.3, p.365-313, 2004.

HARRY, B.; STURGES, K. M.; KLINGNER, J. K. Mapping the Process: An Exemplar of Process and Challenge in Grounded Theory Analysis. Educational Researcher, v. 34, n.2, p.3-13, mar. 2005.

HRUSCHKA, D. J. et al. Reliability in coding open-ended data: lessons learned from HIV behavioral research. Field Methods; v.16, p.307-331, 2004.

JOHNSON, R. B.; Onwuegbuzie, A. J. Mixed Methods Research: A Research Paradigm Whose Time Has Come. Educational Researcher, v.33, n.7, p.14-26, Oct. 2004.

LIMA, L. C. A formação de professores de ciências: uma abordagem epistemológica. Dissertação (Mestrado em Educação - Educação e Ciência) - Curso de Pós-Graduação em Educação, Universidade Federal de Santa Catarina. Florianópolis, 1999.

MILES, M. B.; HUBERMAN, A. M. (1987). Qualitative Data Analysis, 2. ed. Newbury Park, CA: Sage, Press of America.1994. 


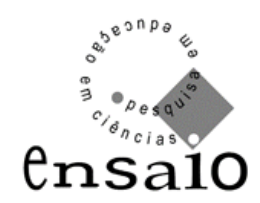

MISLEVY, R. J. Evidence and inference in educational assessment. Psychometrika, v.59, n.4, 439-483.1994.

POLANYI, M. The Tacit Dimension. Gloucester (Mass): Peter Smith. 1983.

SCHUM, D. A. Evidence and inference for the intelligence analyst. Lanham, MD: University. 1987.

SILVA, G. J; MARTINS, C. M. C; BORGES, O. Análise da imagem de ciência nos livros didáticos de química: um desenho metodológico. 2005. In: VII ENPEC. Anais... 2005.

SILVA, G. J; MARTINS, C. M. C. O desafio da confiabilidade na investigação epistemológica nos livros de química. In: XIII ENEQ. Anais... 2006.

SILVA, G. J. A epistemologia-em-uso: Imagens de ciência em livros didáticos de química. Dissertação (Mestrado em Educação). Faculdade de Educação, Universidade Federal de Minas Gerais. 2007.

SMITH, F. Compreendendo a leitura: uma análise psicolinguística da leitura e do aprender a ler. Porto Alegre: Artes Médicas, 1989.

TRIOLA, M. F. Introdução à estatística. 7. ed. Rio de Janeiro: LTC Livros Técnicos e Científicos, 1999.

TROCHIM, W. M. K. Measurement validity types. Disponível no endereço eletrônico http://www.socialresearchmethods.net $/ \mathrm{kb} /$ measval.htm, acessado em 23/08/2005.

TWINING, W. L., Theories of Evidence: Bentham and Wigmore. Stanford: Stanford University Press, 1986.

VERGNAUD, G. La théorie des champs conceptuels. Recherches en Didactique das Mathématiques. v.10, n.23, pp.133-170. Tübingen, 1988.

Data de recebimento: 05/11/08

Data de aprovação: 27/04/09

Data de versão final: 22/06/09 